UDK 001.8(4)"1551/1617"(091)

929 Vrančić, Faust

Primljeno: 8. 4. 2017.

Prihvaćeno: 1. 6. 2017.

Pregledni rad

DOI: $10.22586 /$ pp.v52i 0.2

\title{
Faust Vrančić (1551. - 1617.) i intelektualna kultura njegova doba
}

\author{
Zrinka Blažević \\ Odsjek za povijest \\ Filozofski fakultet Sveučilišta u Zagrebu \\ Ivana Lučića 3 \\ 10000 Zagreb \\ Republika Hrvatska \\ E-adresa: zblazevi@ffzg.hr
}

\begin{abstract}
Faust Vrančić (1551. - 1617.) jedan je od najsvestranijih hrvatskih humanistapolihistora koji je svojom znanstvenom, intelektualnom i diplomatsko-političkom aktivnošću na prijelazu iz 16. u 17. stoljeće ostavio neizbrisiv trag ne samo u hrvatskoj, nego i u europskoj znanosti i kulturi. U maniri tipičnoga kasnohumanističkog erudita Vrančić je asimilirao, kombinirao, ali i kreativno modificirao elemente raznovrsnih intelektualnih tradicija koje su oblikovale složenu strukturu renesansne episteme, od aristotelizma i skolastike do renesansnoga humanizma i reformnoga katolicizma. Slijedom toga, u radu će se na primjeru Vrančićevih djela tehničke, jezikoslovne, filozofske, hagiografske i povijesne tematike nastojati osvijetliti složena konfiguracija kasnohumanističke intelektualne kulture na razmeđu Sredozemlja i Srednje Europe čijim je Vrančić bio ne samo iznimno kompetentnim dionikom, nego ju je i uvelike obogatio svojim inovativnim i imaginativnim intelektualnim zamislima i rješenjima.
\end{abstract}

Ključne riječi: Faust Vrančić, renesansna epistema, intelektualna kultura, 16. stoljeće

Faust Vrančić (1551. - 1617.) jedan je od najsvestranijih hrvatskih humanistapolihistora koji je svojom znanstvenom, intelektualnom i diplomatsko-političkom aktivnošću na prijelazu iz 16. u 17. stoljeće ostavio neizbrisiv trag ne samo u hrvatskoj, nego i u europskoj znanosti i kulturi. ${ }^{1}$ U maniri tipičnoga kasnohu-

1 Ovo je prerađena i dopunjena verzija izlaganja na Znanstvenome kolokviju o Faustu Vrančiću održanome 3. listopada 2016. godine u Rimu u suorganizaciji Papinskoga hrvatskog zavoda sv. Jeronima u Rimu, projekta HAZU “Upoznajmo hrvatsku znanstvenu baštinu” i Hrvatske udruge Machinae novae. 
manističkog erudita Vrančić je asimilirao, kombinirao, ali i kreativno modificirao elemente raznovrsnih intelektualnih tradicija koje su oblikovale složenu strukturu renesansne episteme, od aristotelizma i skolastike do renesansnoga humanizma i reformnoga katolicizma. Razloge te simbioze treba s jedne strane tražiti u njegovu životopisu i intelektualnoj formaciji na razmeđu kasnohumanističke sredozemne i ranoapsolutističke srednjoeuropske kulture, a s druge strane u utjecaju povijesnoga konteksta.

Vrančićev životni i obrazovni put obilježio je utjecaj različitih kulturnih sfera. ${ }^{2}$ Nakon djetinjstva provedenoga u rodnome Šibeniku, važnome centru dalmatinske humanističke kulture, stric Antun uzeo je mladoga Fausta na školovanje u Požun. ${ }^{3}$ Taj se grad profilirao u jedno od najvažnijih intelektualnih središta Ugarskoga Kraljevstva, ponajprije zahvaljujući činjenici da je ondje u drugoj polovici 15. stoljeća djelovalo sveučilište (Universitas Istropolitana) osnovano na poticaj kralja Matije Korvina 1465. godine s ciljem promoviranja humanističke naobrazbe i kulturnoga stvaralaštva. ${ }^{4} \mathrm{U}$ doticaj pak s talijanskom kasnohumanističkom znanstvenom kulturom Faust dolazi u vrijeme studija filozofije i prava u Padovi između 1568. i 1572. godine ${ }^{5}$ da bi se naposljetku upoznao i sa srednjoeuropskom manirističkom učenošću, tehničkom vještinom i umjetničkom praksom boraveći trinaest godina kao tajnik na dvoru cara Rudolfa II. Habsburškoga (1576. - 1612.) u Pragu. ${ }^{6} \mathrm{Za}$ Vrančićevu intelektualnu formaciju od neprijeporne je važnosti bio i ulazak u svećenički red i dugogodišnji boravak u Rimu gdje je imao prigodu asimilirati ideološko-političke smjernice, ali i najvažnije odrednice kulturnoga programa poslijetridentskoga reformnog katoličanstva. Stoga bi se s pravom moglo zaključiti da je upravo taj intelektualni amalgam, nastao kao rezultat mnogobrojnih i višesmjernih intelektualnih i kulturnih razmjena i prožimanja, bio

2 O Vrančićevu osobnom životu i profesionalnoj biografiji detaljnije usp.: Vladimir Muljević, "Hrvatski znanstvenici Antun i Faust Vrančić”, Encyclopaedia moderna XIV (1993), br. 2 (42): 122-136; Vladimir Muljević, Faust Vrančić, prvi hrvatski izumitelj (Zagreb: Hrvatska zajednica tehničke kulture, 1998); Žarko Dadić, "Faust Vrančić, život i prirodoznanstveni rad u Faust Vrančić", u: Faust Vrančić, Machinae novae Fausti Verantii Siceni cum declaratione Latina, Italica, Hispanica, Gallica et Germanica, prev. Vladimir Muljević (Zagreb, pretisak: Novi liber; Šibenik: Gradska knjižnica “Juraj Šižgorić”, 1993), 147-151.

3 O šibenskome humanističkom krugu usp.: Marin Frančević, Franjo Švelec, Rafo Bogišić, Povijest hrvatske književnosti, knjiga 3. od renesanse do prosvjetiteljstva (Zagreb: Liber; Mladost, 1974), 41-44; Milivoj Zenić, U pohvalu od grada Šibenika: pisana riječ o najstarijih vremena do danas (Šibenik: Gradska knjižnica "Juraj Šižgorić", 2002), 51-147.

4 Detaljnije usp.: Eva Frimmová, “Der Humanismus in Pressburg am Ausgang des Mittelalters”, u: Verdrängter Humanismus-Verzögerte Aufklärung, ur. Michael Benedikt, Reinhold Knoll, Josef Rupitz (Klausen-Leopoldsdorf: Verlag Leben-Kunst-Wissenschaft, 1996), 273-292. O humanističkoj kulturi u doba Matije Korvina usp.: Tibor Klaniczay, József Jankovics, ur., Matthias Corvinus and Humanism in Central Europe (Budapest: Balassi Kiadó, 1994).

5 O kurikulu i organizaciji studija filozofije i prava na padovanskome sveučilištu u ranome novom vijeku usp.: Paul F. Grendler, The Universities of Italian Renaissance (Baltimore; London: The John Hopkins University Press, 2002), 3-41, 353-392, 431-456.

6 O manirističkoj kulturi na Rudolfovu dvoru usp. do danas neprevladanu intelektualnopovijesnu studiju R. J. W. Evansa, Rudolf II and His World (Oxford: Oxford University Press, 1973). 
svojevrsnim katalizatorom, ali i dominantnim obilježjem cjelokupna Vrančićeva stvaralaštva.

Što se pak povijesnoga konteksta tiče, kraj 16. i početak 17. stoljeća na vjerskopolitičkome planu obilježavao je sve intenzivniji zamah posttridentinskoga katoličanstva. Naime, premda je neposredni motiv sazivanja općega ekumenskog crkvenog sabora u Tridentu bilo traženje adekvatnoga teološkog i eklezijalnog odgovora na protestantski izazov, tijekom njegova višegodišnjeg zasjedanja (1545. - 1563.), usprkos brojnim dogmatskim razmiricama i neslaganjima, razrađen je model kompleksne i korjenite reforme in capite et in membris, čime su konkretizirane mnoge od reformističkih ideja koje su unutar Katoličke crkve latentno tinjale još od 15. stoljeća. Tako je osmišljen i sveobuhvatni program institucionalnoga preustroja gotovo svih segmenata Katoličke crkve, a normirane su i legitimne forme i modaliteti vjerske prakse. Stoga je Katolička crkva početkom 17. stoljeća u pogledu univerzalističkih političkih pretenzija mogla postati ne samo dostojan partner ranomoderne države, koja se konstituirala na načelima apsolutističke doktrine, nego je bila i spremna uhvatiti se u koštac s dva najveća izazova - kristijanizacijom nevjernika i obraćenjem raskolnika.

Osim toga, prijelaz iz 16. u 17. stoljeće obilježava i uzlet protonacionalih ideologema poput njemačkoga teutonizma, poljskoga sarmatizma i mletačkoga henetizma, koji su katalizatorski djelovali na humanistički ilirizam, a čijim je epicentrom bio dalmatinski kulturni krug. ${ }^{7}$ Humanistički ilirizam je, slično kao u susjednoj Italiji, nastao dijelom kao konkretan izraz identifikacijsko-legitimacijskih potreba dalmatinskih komuna suočenih s jedne strane s mletačkim ekspanzionizmom, a s druge strane s osmanskom kulturnom i civilizacijskom prijetnjom, a dijelom i kao simbolična aproprijacija univerzalističkih i integralističkih elemenata koji su tijekom 16. stoljeća bili osnovna sastavnica političkih programa vodećih i svjetovnih i duhovnih političkih sila. U slučaju dalmatinskih humanističkih ilirizama protonacionalno-identifikacijska matrica realizirat će se u komplementarnoj trijadi komunalnoga, regionalnoga - dalmatinskoga i nacionalnoga - ilirskoga. ${ }^{8}$

\footnotetext{
7 Humanistički ilirizam jest diskurzivni proizvod južnoslavenske grane humanističke res publica litteraria, koja je od kraja 15. stoljeća bila intenzivno angažirana na projektu simboličnoga konstruiranja ilirskoga protonacionalnog identiteta. Poput ostalih protonacionalnih ideologema ilirski ideologem može se definirati kao povijesno određen pojmovni ili značenjski kompleks intertekstualnoga karaktera i velikoga performativnog potencijala, koji istodobno tematizira i "proizvodi” zajedničko podrijetlo, jezično jedinstvo, teritorijalnu rasprostranjenost i iznimne kvalitete Ilira, različito identificiranih unutar etničkoga opsega slavenstva. Sukladno postulatima suvremenih teorija nacije, koje proces formiranja kolektivnih identiteta smještaju u predmoderno razdoblje, ranonovovjekovni ilirizam može se smatrati diskurzivnim i ideologijskim prethodnikom istoimenoga devetnaestostoljetnog nacionalno-identifikacijskog modela. Detaljnije usporedi: Zrinka Blažević, Ilirizam prije ilirizma (Zagreb: Golden marketing i Narodne novine, 2008).

8 O dalmatinskome ilirizmu usporedi: Zrinka Blažević, "Između komunalnog patriotizma i protonacionalnog univerzalizma: identitetski modeli u ranomodernoj dalmatinskoj historiografiji”, u: Dalmatien als europaeischer Kulturraum:Beitraege zu den Internationalen wissenschaftlichen Symposien "Dalmatien als Raum europaeischer Kultur synthese" (Bonn, 6.-10. Oktober 2003) und "Städtische Kultur in Dalmati-
} 
Osim kasnohumanističkoga dalmatinskog ilirizma na Vrančićevu je ideološko-političku koncepciju utjecao i reformnokatolički ilirizam. Njegovo je glavno obilježje strukturna i funkcionalna interferencija s ideologijskim postulatima i političkim ciljevima posttridentinskoga reformnog katoličanstva, koji se najopćenitije manifestiraju u vidu dva paralelna i komplementarna procesa: interne institucionalno-dogmatske konsolidacije i eksterne ekspanzije. Sukladno tome, temeljna odrednica reformnokatoličkoga ilirizma jest njegova institucionalna situiranost motivirana potrebama što efikasnije referencijalne realizacije. Zahvaljujući tome biva involviran i integriran u različite mreže i mehanizme političke i kulturne moći te na taj način postaje ne samo konstitutivnim elementom simbolične političke prakse Katoličke crkve, nego i sredstvom akumulacije te medijem investiranja individualnoga i kolektivnoga simboličnog kapitala. Institucionalnim središnjicama oko kojih se tijekom 17. stoljeća pod neposrednim utjecajem Kongregacije za širenje vjere ideologijski formirao i diskurzivno formulirao reformnokatolički ilirizam bili su Ilirski kolegij u Loretu i Zavod svetoga Jeronima u Rimu, a čijim je članom Faust Vrančić postao 1. siječnja 1575. godine. ${ }^{9}$ Aktivnost tih institucija bila je upravljana tridentinskim načelima širenja pravovjerja i to kako neposredno, kanonskim misijama i vizitacijama na terenu, tako i posredno, obrazovanjem budućega svećeničkog kadra te proizvodnjom i distribucijom liturgijske i katehetske literature na vernakularu, što je svakako moglo poslužiti i kao motiv objavljivanja Vrančićeva peterojezičnog rječnika.

Važna karakteristika reformnokatoličkoga ilirizma, a ujedno poveznica s njegovim diskurzivnim prethodnicima poput humanističkoga dalmatinskog ilirizma, jest antiosmanska mobilizatorska dimenzija, što je bilo osobito izraženo u doba ratova s Osmanskim Carstvom. Antiosmanska akcija i konfesionalna unifikacija predstavljali su zajedničku platformu na kojoj se realizirala organska, premda uvijek konfliktna, suradnja Katoličke crkve i Habsburgovaca te ostalih katoličkih europskih vladara u cilju realizacije vlastitih univerzalističkih i hegemonističkih težnji. U tome se svjetlu može tumačiti i stvaranje velikih sakralno-svjetovnih protuturskih koalicija koje su obilježile period takozvanoga Dugog rata (1591. - 1606.), koji je odigrao važnu ulogu u oblikovanju Vrančićeva "dalmatinskog sarmatizma."10

Naposljetku valja upozoriti i na začetak apsolutističkih tendencija koje su u sferi političke teorije i prakse unutar habsburške domene bile vidljive već u doba

en. Die Genese eines europaeischen Kulturraums", ur. Wilfried Potthoff, Aleksandar Jakir, Marko Trogrlić, Nikolaus Trunte (Split: Filozofski fakultet, 2010), 93-129.

9 Usp. Josip Burić, Iz prošlosti hrvatske kolonije u Rimu (Rim: Knjižnica novog života, 1966), 13.

${ }^{10}$ Detaljnije usp.: Zrinka Blažević, “'Dalmatinski' sarmatizam Fausta Vrančića (1551. - 1617.) - paradigmatski model humanističke kulturne translacije", u: Faust Vrančić i njegovo doba. Zbornik radova s Medunarodnog znanstvenog skupa održanog u povodu 400. obljetnice objavljivanja Novih strojeva Fausta Vrančića, ur. Marijana Borić, Zrinka Blažević, Bojan Marotti (u tisku). 
Vrančićeva patrona, cara Rudolfa II., da bi svoj zenit dosegle za njegovih nasljednika Ferdinanda II. (1619. - 1637.), Ferdinanda III. (1637. - 1657.) i Leopolda I. (1657. - 1705). Ideološko-politički profil habsburške apsolutističke doktrine mogao bi se najbolje opisati kao eklektički konglomerat tradicionalne srednjovjekovne teološke monarhijske paradigme, kasnohumanističkoga neostoicizma i učenja o državnome razlogu prilagođenoga duhu reformnokatoličke moralne filozofije, ${ }^{11}$ čiji se formativni utjecaj opaža i u Vrančićevu političkom dekalogu objavljenome u sklopu Kršćanske etike. Na koncu valja istaknuti da je reflekse opisane ideološke i političke konjunkture moguće detektirati u cjelokupnoj Vrančićevoj književnoj proizvodnji čiji se kreativni dosezi i kulturnopovijesno značenje stoga mogu adekvatno valorizirati jedino iz perspektive toga, u intelektualnome i političkome smislu, tranzicijskoga doba.

Epistemički utjecaji kasnorenesansnoga humanizma s kojime je Vrančić došao u doticaj tijekom studija u Padovi i Veneciji ogledaju se ponajviše u Vrančićevoj zbirci crteža i opisa tehničkih izuma Machinae novae, filozofskome djelu Logica nova i petojezičnome Rječniku. Naime, 1560-ih godina na padovanskome se sveučilištu počinje predavati mehanika, koja se temeljila na latinskome prijevodu Pseudo-Aristotelova djela Problemata mechanica. ${ }^{12}$ Riječ je o raspravi koja se danas pripisuje Aristotelovu učeniku Stratonu (4. stoljeće prije Krista). To djelo sintetizira arhimedovsku tradiciju i elemente peripatetičke prirodne filozofije te je očito utjecalo i na načela srednjovjekovne mehanike, koja je artikulirao Giordano iz Nema (13. stoljeće). ${ }^{13}$ Sukladno programskim smjernicama apostrofiranima u uvodu Mehaničkih problema, mehanika se držala takozvanom posredničkom znanošću smještenom između matematike i prirodne filozofije. ${ }^{14}$ Osim toga, $\mathrm{u}$ tome se djelu mehanika po prvi puta instituira kao teorijska znanost koja mora imati poveznice s matematikom, unatoč činjenici da njezin predmet interesa pripada domeni prirodnoga svijeta. Kada je pak o njezinoj funkciji riječ, u tome se kanonskome renesansnom priručniku mehanika definirala kao znanost koja se bavi kretanjem i njegovim učincima koji nisu isključivo prirodni nego mogu biti čak i suprotni prirodnim zakonima jer "ono što čini priroda djeluje na samo jedan način, dok ono što koristi ljudima može djelovati na više različitih načina." ${ }^{15}$ Slijedom toga svrha mehanike mora biti primarno utilitarna i to u smislu zadovo-

\footnotetext{
${ }^{11} \mathrm{O}$ ideološkoj strukturi habsburške apsolutističke doktrine usp.: Zrinka Blažević, Vitezovićeva Hrvatska između stvarnosti i utopije (Zagreb: Barbat, 2002), 40-52.

${ }^{12} \mathrm{O}$ studiju i predavačkima mehanike na padovanskome sveučilištu usp.: Walter Roy Laird, "The Scope of Renaissance Mechanics", Osiris 2 (1986): 43-68. O razvoju mehanike u okviru talijanske, španjolske i nizozemske ranonovovjekovne prirodnoznanstvene kulture usp.: Walter Roy Laird, Sophie Roux, ur., Mechanics and Natural Philosophy before the Scientific Revolution (Berlin: Springer, 2008).

${ }^{13}$ Podrobnije o tome djelu usp.: Paul Lawrence Rose, Stillman Drake, "The Pseudo-Aristotelian Questions of Mechanics in Renaissance Culture", Studies in the Renaissance 18 (1971): 65-104.

${ }^{14}$ Laird, "The Scope", 46.

${ }^{15}$ Cit. prema Laird, "The Scope”, 46.
} 
ljavanja specifično ljudskih potreba. Takvo je shvaćanje mehanike u cijelosti bilo komplementarno s manirističkim idealom povezivanja tehničke vještine, invencije i ingenioznosti u svrhu iskorištavanja magičnih sila prirode kojim su se, osim Vrančića, vodili i ostali crtači mehaničkih naprava na Rudolfovu dvoru u Pragu poput Jacopa i Octavija Strade. Prema manirističkome je vjerovanju, naime, stroj bio svojevrsna "živa igračka" koja je reproducirala generativnu snagu prirode zbog čega su mu se pridavala čak i divinatorna i proročka značenja. ${ }^{16}$

U tematskome su pak fokusu Pseudo-Aristotelovih Mehaničkih problema bila načela kružnoga kretanja, čija je brzina sukladna udaljenosti točke u odnosu na središte kruga, što se praktično ekspliciralo na primjerima funkcioniranja njihala i poluge. ${ }^{17}$ Kako se i u Vrančićevu djelu Machinae novae mnogo praktično funkcionalnih izuma temelji na načelu kružnoga kretanja, čini se da je - uz manirizmom nadahnute radove pripadnika praškoga znanstvenog kruga i talijanskoga barnabita Giovannija Ambrogia Mazente (1565. - 1635.) - i ova kanonska renesansna rasprava o mehanici mogla biti važnim izvorištem inspiracije za Vrančićeve Nove strojeve. ${ }^{18}$

Renesansni humanizam supstrat je i Vrančićeva djela Logica nova ${ }^{19} \mathrm{U}$ otklonu spram aristotelizma takozvane padovanske škole, Vrančić se u epistemološkoj konceptualizaciji logike oslanjao na platonističku tradiciju koju je promovirala takozvana jezuitska škola. ${ }^{20}$ Slijedom toga, Vrančić logiku definira instrumentalistički, kao metodu razlaganja i naučavanja već poznatoga, za razliku od prirodoznanstvenoga aristotelizma koji u prvi plan stavlja njezine spoznajne funkcije. ${ }^{21}$ Jednako tako, na mjesto logičke metode regressus, koju je preferirao skolastički

\footnotetext{
${ }^{16}$ O tome usp.: Evans, Rudolf II, 186-187.

${ }_{17}$ Usp. Laird, “The Scope", 47.

${ }^{18}$ O koncepciji, strukturi i sadržaju Vrančićevih Novih strojeva instruktivno usp.: Marijana Borić, "Osobitosti Vrančićevih tehničkih konstrukcija u vezi s razvojem matematike i njene primjene u znanosti i tehnici", u: Faust Vrančić i njegovo doba. Zbornik radova s Međunarodnog znanstvenog skupa održanog u povodu 400. obljetnice objavljivanja Novih strojeva Fausta Vrančića, ur. Marijana Borić, Zrinka Blažević, Bojan Marotti (u tisku). O tome kapitalnom Vrančićevu djelu također usp.: Friedrich Klemm, Adolf Wissner, Fausto Veranzio und seine "Machinae novae" (München: Heinz Moos Verlag, 1965); Vladimir Muljević, Faust Vrančić prvi hrvatski izumitelj (Zagreb: Hrvatska zajednica tehničke kulture, 1998); Žarko Dadić, Hrvati i egzaktne znanosti u osvitu novovjekovlja (Zagreb: Naprijed, 1994), 124-134; Dražen Mirko Grmek, "Verantius, Faustus", Dictionary of Scientific Biography, Vol. XIII (New York: Scribner's Sons, 1976), 613-614.

${ }_{19}$ Vrančićevo djelo Logica suis ipsius instrumentis formata et recognita (Logika oblikovana i objašnjena vlastitim oruđima) doživjelo je dva izdanja. Prvi je put objavljeno u Veneciji 1608. godine kod izdavača Giovannija Albertija, dok je drugo izdanje objavljeno 1616. godine kod izdavača Ambrogija i Bartola Deija pod dopunjenim naslovom Logica nova suis ipsius instrumentis formata et recognita. O tome Vrančićevu djelu usp.: Šime Jurić, "Nepoznata izdanja 'Logike i etike’ Fausta Vrančića”, Prilozi za istraživanje hrvatske filozofske baštine 4/1-2 (7-8) (1978): 289-294; Srećko Kovač, "Logika Fausta Vrančića”, Prilozi za istraživanje hrvatske filozofske baštine 10/1-2 (19-20) (1984): 39-48; Srećko Kovač, "Faust Vrančić i aristotelizam u logici”, Prilozi za istraživanje hrvatske filozofske baštine 14/1-2(27-28) (1988): 17-33.

${ }^{20}$ Detaljnije o tome usp.: Kovač, "Faust Vrančić i aristotelizam”, 30-32.

${ }^{21}$ Usp.: Kovač, "Faust Vrančić i aristotelizam”, 30.
} 
aristotelizam, Vrančić inaugurira metodu divizije, što je posve u suglasju s njegovim humanističkim afinitetima prema retorici. ${ }^{22}$ Slijedom toga moglo bi se zaključiti da je Vrančićeva koncepcija logike u cijelosti korespondirala s njegovim poimanjem mehanike kao primijenjene znanosti odnosno stroja kao praktične materijalizacije teorijskih postulata prirode filozofije. ${ }^{23}$

Ideološki i kulturni utjecaji renesansnoga humanizma, ali sa snažnim ideološkim pečatom reformnokatoličkoga ilirizma, opažaju se i kada je riječ o Vrančićevu peterojezičnom rječniku, čije je prvo izdanje objavljeno u Veneciji 1595. godine. ${ }^{24}$ Naime, dok formalna i strukturna obilježja Dictionarium svrstavaju u red najkvalitetnijih sljednika kanonskoga humanističkog višejezičnog rječnika Ambrogija Calepina (1440. - 1510.), njegova je pragmatična funkcija bila dvojaka. ${ }^{25}$ Ona je s jedne strane odražavala smjernice reformnokatoličke jezične politike Rimske kurije, o čemu nedvojbeno svjedoče i Vrančićeve veze s isusovačkim jezičnim reformatorom Alfonsom Carrilliom (1553. - 1618. $)^{26}$, a s druge je strane reproducirala

\footnotetext{
${ }^{22}$ Metoda regressus sastavni je dio silogističkoga dokaznoga postupka, a gradi se nadovezivanjem kompozitivne metode na rezolutivnu. Najprije se polazi od onoga što je poznatije za nas i ide se do poznatijega po prirodi, a potom se provjerava prethodni postupak tako da se krene od poznatijega po prirodi i dođe do poznatijega za nas. Metoda divizije, pak, započinje raščlanjivanjem cjeline u dijelove, a potom se dijelovi iznova sastavljaju u cjelinu. Za podrobnu raščlambu strukture i funkcija obiju logičkih metoda u kontekstu renesansne logike usporedi: Luka Boršić, Ivana Skuhala Karasman, "Vrančićevo djelo Logica nova suis ipsius instrumentis formata et recognita", u: Faust Vrančić i njegovo doba. Zbornik radova s Medunarodnog znanstvenog skupa održanog u povodu 400. obljetnice objavljivanja Novih strojeva Fausta Vrančića, ur. Marijana Borić, Zrinka Blažević, Bojan Marotti (u tisku).

${ }^{23}$ To je implicitno sugerirao i Srećko Kovač lucidno povlačeći analogiju između Vrančićeva rječnika i stroja: "Ni poznati Vrančićev rječnik nije drugo nego konstrukcija stroja koji, kad se ubaci neka informacija (određena latinska riječ), automatski izbacuje neku drugu, traženu informaciju (odgovarajuću talijansku, njemačku, hrvatsku ili mađarsku riječ)., Kovač, "Faust Vrančić i aristotelizam”, 30.

${ }^{24}$ O Vrančićevu rječniku postoji opsežna jezikoslovna i književnopovijesna literatura. Za kratak pregled starijih radova usporedi: Josip Lisac, "Hrvatski jezik i Faust Vrančić, s osobitim obzirom na Život nikoliko izabranih divic", u: Faust Vrančić, Život nikoliko izabranih divic (Šibenik: Gradska knjižnica "Juraj Šižgorić”, 1995), 145-147. U novije vrijeme Vrančićevim su se rječnikom bavili jezikoslovac Josip Lisac i Sanja Vulić. Usp.: Josip Lisac, Faust Vrančić i drugi. Jezičnopovijesni ogledi (Šibenik: Gradska knjižnica "Juraj Šižgorić", 2004); Josip Lisac, "Hrvatski jezik Vrančićeva rječnika i njegove proze", Filologija 59 (2013): 37-47; Sanja Vulić, "Još ponešto o Vrančićevim nazivima mjeseci u godini", Čakavska rič XLIV (2016), 1-2: 131-139; Sanja Vulić, "Vrančićev leksik u kontekstu hrvatskoga leksika u prošlosti i sadašnjosti”, u: Faust Vrančić i njegovo doba. Zbornik radova s Medunarodnog znanstvenog skupa održanog u povodu 400. obljetnice objavljivanja Novih strojeva Fausta Vrančića, ur. Marijana Borić, Zrinka Blažević, Bojan Marotti (u tisku).

${ }^{25}$ Za komparativnu analizu Vrančićeva i Calepinova rječnika Dictionarium undecim linguarum (Basiliae, 1590), usp.: Marianna D. Birnbaum, "Ambrogio Calepino i Faust Vrančić", u: Zbornik o Faustu Vrančiću. Zbornik radova sa znanstvenog skupa "Obitelj Vrančić u hrvatskoj književnosti i znanosti", Šibenik 12.-14. rujna 1995, ur. Vilijam Lakić (Šibenik: Gradska knjižnica "Juraj Šižgorić", 2001), 31-35. i Emese Fazekas, "Petojezični rječnik Fausta Vrančića, jedna od prvih jezikoslovnih riznica”, u: Zbornik o Faustu Vrančiću, 37-43.

${ }_{26}$ Španjolski isusovac Alfonso Carrillio (Alcalá de Henares, 1553. - 1618.) zalagao se za podučavanje hrvatskoga jezika u isusovačkim kolegijima, što je Vrančiću svakako mogao biti važan motiv zbog čega je upravo njemu posvetio svoj peterojezični rječnik. Osim toga, Carillio, koji je 1601. godine postao provincijalom austrijske isusovačke provincije, uvelike je zaslužan za osnivanje zagrebačkoga isusovačkog
} 
tipične koncepcije onodobnih europskih protonacionalnih ideologema. Oni su, naime, ključnim nacionalno-integracijskim čimbenikom držali upravo zajednički narodni jezik. ${ }^{27}$ Vrančićeva koncepcija o slavenskome jezičnom jedinstvu najeksplicitnije je artikulirana u predgovoru Lodereckerova rječnika objavljenoga u Pragu 1605. godine. ${ }^{28}$ Vrančićev je neposredni diskurzivni i ideološki uzor za to bio suvremeni poljski sarmatizam koji je, kao što će se kasnije detaljnije obrazložiti, imao i najvažnijega utjecaja na cjelokupnu Vrančićevu ideološko-političku platformu. To se najjasnije može detektirati u Vrančićevoj formulaciji da je slavenski jezik najveći na svijetu jer obuhvaća "dobar dio Europe i Azije," što je standardni element sarmatističkoga ideologemskog repertoara. ${ }^{29}$ Specifični "dalmatinski” pečat Vrančićevu pak jezičnome programu daje konstatacija da je jezik kojim govore Slaveni u Dalmaciji “čišći” od češkoga, poljskoga i ruskoga, što ga čini idealnim komunikacijskim, integracijskim, ali i prozelitističkim medijem. ${ }^{30}$ Ta se intencija vrlo jasno može razabrati i iz strukture Vrančićeve lingvističke koncepcije implementirane u peterojezičnome rječniku, koja se u leksičkome pogledu temelji na trodijalektalnosti te kombinaciji sjevernih i južnih pravopisnih i grafijskih načela. ${ }^{31}$ Formativni utjecaji poljskoga sarmatizma na Vrančićevu ideološko-političku koncepciju najevidentniji je u polemičkoj poslanici De Slovvinis seu Sarmatis, upućenoj krakovskome kanoniku Krzysztofu Warszewickomu (1543. - 1603.) . $^{32}$ i objavljenoj u dodatku Vrančićeva hagiografskog djela Život nikoliko izabranih divic iz 1606. godine. ${ }^{33}$ Poput sarmatizma i Vrančićeva se protonacionalna ideo-

kolegija kao važnoga institucionalnog središta za provedbu posttridentske reformnokatoličke politike u Hrvatskome Kraljevstvu. O odnosima Vrančića i Carrilija usp.: Vladimir Horvat, "Faust Vrančić i isusovci Alfonso Carrillio i Bartol Kašič", u: Zbornik o Faustu Vrančiću, 7-13.

${ }^{27}$ O tome detaljnije usporedi: Blažević, Ilirizam, 101-103.

${ }^{28}$ Usp.: Peter Loderecker, Dictionarium septem diversarum linguarum, videlicet Latine, Italice, Dalmatice, Bohemice, Polonice, Germanice et Ungarice etc., Prag, 1605, s. p.

${ }^{29}$ O sarmatističkome toposu jezičnoga jedinstva detaljnije usporedi: Blažević, Ilirizam, 82-83.

30 “(...) oni Slaveni koji žive u Dalmaciji i susjednim pokrajinama čistoćom svoga govora daleko iza sebe ostavljaju svoje praroditelje, naime Poljake, Čehe i Ruse, i to ne samo svoje suvremenike nego i one stare, što se može zaključiti iz knjiga, iako ih je u usporedbi s njima vrlo malo. Ovdašnji, naime, osim osebujnosti i duljine riječi te čestote samoglasnika što je imaju, što mu drago lako izgovaraju i razlikuju padeže i rodove, načine i vremena. Oni drugi okrnjuju riječi, izbacuju samoglasnike i mnogo toga izgovaraju šuškavo i piskavo." Faust Vrančić, "O Slavenima ili Sarmatima”, u: Vrančić, Život, 118.

${ }^{31}$ O Vrančićevu kulturno-jezičnom programu iz perspektive njegove leksikološke djelatnosti usporedi: Josip Vončina, "Vrančićev rječnik", Filologija 9 (1979): 7-36.

${ }^{32}$ Krzysztof Warszewicki (1543. - 1603.) bio je poznati poljski povjesničar, politički publicist, govornik i diplomat. Studirao je u Leipzigu, Wittenbergu i Bologni. Bio je mentorom i učiteljem poljskoga kralja Sigismunda III. Vase (1566. - 1632.). Između 1593. i 1594. godine boravio je na švedskome dvoru, nakon čega se zajedno s kraljem Sigismundom III. vraća u Poljsku gdje piše svoja najvažnija djela: De optimo statu libertatis libri duo (Krakov, 1598) i Paradoxa, quibus de origine generis et nominis Poloni adiunctus est dialogus (Rim, 1601). Detaljnije usporedi: Robert L. Ferring, "Christopher Varsevicius, Polish Renaissance Diplomat, Statesman and Political Writer", The Polish Review 5 (1960), br. 2: 98-109.

${ }^{33}$ Latinski izvornik usp.: Faust Vrančić, Xivvot nikoliko izabranih divvicz (Romae: apud Aloisium Zannettum, 1606), 117-119. Hrvatski prijevod usp.: Vrančić, Život, 117-119. 
loška koncepcija temeljila na trima toposima: toposu o zajedničkome drevnom podrijetlu Slavena izjednačenih sa Sarmatima, njihovoj teritorijalnoj rasprostranjenosti između Dona, Visle, Dnjepra te Crnoga i Baltičkoga more kao i jezičnome jedinstvu. ${ }^{34}$ Praktični poticaj i pragmatično-politički motiv za artikulaciju ovakve Vrančićeve ideološke koncepcije mogla je biti činjenica da je upravo na razmeđu 16. i 17. stoljeća aktualni papa Klement VIII. (1592. - 1605.) nastojao stvoriti snažnu protuosmansku koaliciju koju bi činili habsburški car Rudolf II., poljski kralj Sigismund III. Vasa (1566. - 1632.) i Mletačka Republika. ${ }^{35}$ Slijedom toga Vrančićeva bi se ideološka platforma mogla protumačiti kao poticaj za stvaranje ideologijsko-legitimacijskoga uporišta za protuosmansku koaliciju tih triju reformnokatolički orijentiranih središta političke i vojne moći, koja je trebala osigurati konačnu prevlast kršćanskih snaga u Dugome ratu.

Bliskost s teološko-dogmatskim postulatima, ali i praktično-političkim intencijama posttridentinskoga reformnog katolicizma, otkrivaju i posljednja Vrančićeva djela: vernakularni Život nikoliko izabranih divic i latinska Ethica Christiana. ${ }^{36}$ Zbirka hagiografija, Život nikoliko izabranih divic, posvećena opatici i redovnicama šibenskoga samostana Sv. Spasa, oslanja se na tradiciju srednjovjekovnih života svetaca, ali uz znatnu prisutnost humanističkoga retoričko-poetičkoga inventara. ${ }^{37}$ To se na strukturnoj razini očituje u frekventnoj uporabi i stilskome oblikovanju dijaloških sekvenci, a na sadržajnoj u brojnim referencama na likove iz antičke povijesti i mitologije. ${ }^{38}$ Iako je temeljna funkcija Vrančićeve hagiografije bila vjersko-utilitarna, odnosno vodila se poglavito posttridentinskom politikom formacije egzemplarne ženske pobožnosti, ne smiju se zanemariti ni njezini prozelitistički aspekti. Naime, većina od dvanaest svetica, životopisi kojih su

\footnotetext{
${ }^{34} \mathrm{O}$ utjecaju sarmatističkoga ideologema na ideološku strukturu Vrančićeve protonacionalne koncepcije usporedi: Blažević, "Dalmatinski' sarmatizam” (u tisku).

${ }^{35}$ Najbolji izvor podataka o toj papinskoj inicijativi predstavlja izvješće Paola Parutija, mletačkoga diplomatskog predstavnika pri Svetoj Stolici, napisano u veljači 1596. godine. Paruti tako piše da papa Klement VIII. izražava priličnu skepsu prema sposobnostima cara Rudolfa II., no da ga ipak smatra ključnim koalicijskim partnerom. Nasuprot tome, papa iznimno cijeni i hvali vojničke vrline i vjerski žar Sigismunda III. Vase. Stoga od Signorije traži da mu pomogne osigurati novčana sredstva tvrdeći da je poljski kralj obećao pružiti saveznicima vojnu pomoć ako mu se obeća subvencija u iznosu od četiristo tisuća škuda godišnje. Detaljnije usp.: Kenneth M. Setton, Venice, Austria and the Turks in the Seventeenth Century (Philadephia: The American Philosophical Society, 1991), 12-13.

${ }^{36}$ Prvo izdanje Vrančićeva djela Ethica christiana objavljeno je u Rimu 1610. godine. Drugome izdanju djela Logica nova iz 1616. godine pridodana je i neizmijenjena Ethica christiana, koju je na hrvatski jezik preveo Krešimir Čvrljak. Usp.: Krešimir Čvrljak, Kršćanska etika Fausta Vrančića kao filozofija života: u retrospekciji i kontinuitetu prosudbenih odjeka ranije i kasnije etičko-filozofske tradicije (Zagreb: Hrvatsko filozofsko društvo, 1996).

${ }^{37}$ O tome djelu usporedi: Josip Bratulić, "Faust Vrančić, književnik i hagiograf”, u: Vrančić, Život, 123143; Milovan Tatarin, Bludnica i svetica. Starohrvatska legenda o Mariji Egipćanki (Zagreb: Naklada Ljevak, 2003), 245-291; Lahorka Plejić Poje, "Kako jedno zrcalo pričisto: Bartol Kašić i poslijetridentska prozna hagiografija", u: Tridentska baština. Katolička obnova i konfesionalizacija u hrvatskim zemljama. Zbornik radova, ur. Zrinka Blažević, Lahorka Plejić Poje (Zagreb: Matica hrvatska, 2016), 363-376.

${ }^{38}$ Detaljnije usp.: Plejić Poje, “Kako jedno zrcalo (...)”, 370-371.
} 
zastupljeni u Vrančićevoj hagiografiji, pripada kanonu i zapadne i istočne crkve, s time da je štovanje sv. Febronije i sv. Eugenije čak zastupljenije u pravoslavnoj negoli u katoličkoj domeni. ${ }^{39}$ To je bilo posve u skladu s tadašnjom politikom Rimske kurije, koja se od početka 17. stoljeća intenzivno okrenula misiji obraćenja pravoslavnih shizmatika, što je pak do posebnoga izražaja došlo u politici pape Klementa VIII. prema istočnojadranskome prostoru tijekom takozvanoga Dugog rata. ${ }^{40}$

Posljednje Vrančićevo djelo Kršćanska etika, koje predstavlja svojevrsnu teorijsku nadopunu njegovoj hagiografiji, također uvelike slijedi normativne obrasce reformnokatoličke moralne filozofije. Nastavljajući se na kršćansku skolastiku i kauzistiku, ali s mnogobrojnim referencama na antičku, aristotelovsku i platonističku tradiciju moralno-filozofske refleksije, Vrančić trima temeljnim krepostima proglašava poniznost, čistoću i siromaštvo. ${ }^{41}$ Riječ je, dakako, o preferiranim vrlinama iz posttridentinskoga etičkog repertoara koje čine okosnicu i političkoga dekaloga koji Vrančić dodaje na kraju izdanja Kršćanske etike. ${ }^{42}$ Tim se naputcima za dobro i kreposno vladanje "na slavu Boga i dobrobit i korist naroda" Vrančić upisuje u red kasnohumanističkih političkih filozofa koji se - na tragu Boterove adaptacije makijavelističke doktrine o državnome razlogu kršćanskome moralu - smatraju promotorima žanra Speculum principis (Zrcalo vladara). ${ }^{43}$ Taj će odvjetak političke traktatistike posebnu popularnost tijekom 17. stoljeća steći u srednjoeuropskoj kulturnoj domeni s ciljem promidžbe kulta habsburških apsolutističkih vladara. ${ }^{44}$

Već na temelju ove kratke retrospektive Vrančićeva stvaralaštva moguće je steći prilično precizan uvid $\mathrm{u}$ širinu njegove naobrazbe i intelektualnih interesa koji su ga činili kasnohumanističkim eruditom doista europskoga kova. Osim toga, njegova žanrovski i tematski iznimno raznolika djela - u rasponu od mehanike i filozofije do historiografije i hagiografije - bacaju novo svjetlo i na složenu konfiguraciju intelektualne kulture na razmeđu Sredozemlja i Srednje Europe, a čijim je Vrančić bio ne samo iznimno kompetentnim dionikom, nego ju je i uvelike obogatio svojim inovativnim i imaginativnim intelektualnim zamislima i rješenjima.

\footnotetext{
39 Usp.: Bratulić, "Faust Vrančić”, 134-135.

${ }^{40}$ O tome detaljnije usp.: Blažević, Ilirizam, 136-137.

41 Za podrobnu povijesno-filozofsku analizu djela usp.: Črvljak, Kršćanska etika, 47-131.

42 Usp.: Faust Vrančić, “Deset političkih zapovijedi”, u: Čvrljak, Kršćanska etika, 179-181.

${ }^{43}$ O tome žanru pregledno usporedi: Hans-Otto Mühleisen, Theo Stammen, ur., Politische Tugendlehre und Regierungskunst (Tübingen: Niemeyer Verlag, 1990).

${ }^{44} \mathrm{O}$ političkim traktatima u funkciji političke reverencije habsburških careva tijekom 17. stoljeća usporedi: Martin Disselkamp, Barockheroismus. Konceptionen "politischer Größe in Literatur und Traktatistik des 17. Jahrhunderts (Tübingen: Niemeyer Verlag, 2002), 160-232.
} 


\section{Objavljeni izvori i literatura}

Birnbaum, Marianna D. “Ambrogio Calepino i Faust Vrančić”. U: Zbornik o Faustu Vrančiću. Zbornik radova sa znanstvenog skupa "Obitelj Vrančić u hrvatskoj književnosti i znanosti”, Šibenik 12.-14. rujna 1995, uredio Vilijam Lakić, 31-35. Šibenik: Gradska knjižnica “Juraj Šižgorić”, 2001.

Blažević, Zrinka. "Između komunalnog patriotizma i protonacionalnog univerzalizma: identitetski modeli u ranomodernoj dalmatinskoj historiografiji”. U: Dalmatien als europaeischer Kulturraum:Beitraege zu den Internationalen wissenschaftlichen Symposien "Dalmatien als Raum europaeischer Kultur synthese" (Bonn, 6.-10. Oktober 2003) und "Städtische Kultur in Dalmatien. Die Genese eines europaeischen Kulturraums", uredili Wilfried Potthoff, Aleksandar Jakir, Marko Trogrlić, Nikolaus Trunte, 93-129. Split: Filozofski fakultet, 2010.

Blažević, Zrinka. “'Dalmatinski’ sarmatizam Fausta Vrančića (1551. - 1617.) paradigmatski model humanističke kulturne translacije”. U: Faust Vrančić i njegovo doba. Zbornik radova s Međunarodnog znanstvenog skupa održanog u povodu 400. obljetnice objavljivanja Novih strojeva Fausta Vrančića, uredili Marijana Borić, Zrinka Blažević i Bojan Marotti (u tisku).

Blažević, Zrinka. Ilirizam prije ilirizma. Zagreb: Golden marketing i Narodne novine, 2008.

Blažević, Zrinka. Vitezovićeva Hrvatska između stvarnosti i utopije. Zagreb: Barbat, 2002.

Borić, Marijana. "Osobitosti Vrančićevih tehničkih konstrukcija u vezi s razvojem matematike i njene primjene u znanosti i tehnici”. U: Faust Vrančić i njegovo doba. Zbornik radova s Medunarodnog znanstvenog skupa održanog u povodu 400. obljetnice objavljivanja Novih strojeva Fausta Vrančića, uredili Marijana Borić, Zrinka Blažević i Bojan Marotti (u tisku).

Boršić, Luka; Skuhala Karasman, Ivana. "Vrančićevo djelo Logica nova suis ipsius instrumentis formata et recognita". U: Faust Vrančić i njegovo doba. Zbornik radova s Medunarodnog znanstvenog skupa održanog u povodu 400. obljetnice objavljivanja Novih strojeva Fausta Vrančića, uredili Marijana Borić, Zrinka Blažević i Bojan Marotti (u tisku).

Bratulić, Josip. "Faust Vrančić, književnik i hagiograf”. U: Faust Vrančić, Život nikoliko izabranih divic, 123-143. Šibenik: Gradska knjižnica “Juraj Šižgorić”, 1995.

Burić, Josip. Iz prošlosti hrvatske kolonije u Rimu. Rim: Knjižnica novog života, 1966.

Čvrljak, Krešimir. Kršćanska etika Fausta Vrančića kao filozofija života: u retrospekciji i kontinuitetu prosudbenih odjeka ranije i kasnije etičko-filozofske tradicije. Zagreb: Hrvatsko filozofsko društvo, 1996. 
Dadić, Žarko. "Faust Vrančić, život i prirodoznanstveni rad”. U: Faust Vrančić, Machinae novae Fausti Verantii Siceni cum declaratione Latina, Italica, Hispanica, Gallica et Germanica. Pretisak. Preveo Vladimir Muljević, 147-151. Zagreb; Šibenik: Novi liber; Gradska knjižnica "Juraj Šižgorić”, 1993.

Dadić, Žarko. Hrvati i egzaktne znanosti u osvitu novovjekovlja. Zagreb: Naprijed, 1994.

Disselkamp, Martin. Barockheroismus. Konceptionen "politischer Größe in Literatur und Traktatistik des 17. Jahrhunderts. Tübingen: Niemeyer Verlag, 2002.

Evans, R. J. W. Rudolf II and His World. Oxford: Oxford University Press, 1973.

Fazekas, Emese. "Petojezični rječnik Fausta Vrančića, jedna od prvih jezikoslovnih riznica”. U: Zbornik o Faustu Vrančiću. Zbornik radova sa znanstvenog skupa "Obitelj Vrančić u hrvatskoj književnosti i znanosti”, Šibenik 12.-14. rujna 1995, uredio Vilijam Lakić, 37-43. Šibenik: Gradska knjižnica "Juraj Šižgorić”, 2001.

Ferring, Robert L. "Christopher Varsevicius, Polish Renaissance Diplomat, Statesman and Political Writer". The Polish Review 5 (1960), br. 2: 98-109.

Frančević, Marin; Švelec, Franjo; Bogišić, Rafo, ur. Povijest hrvatske književnosti, knjiga 3. od renesanse do prosvjetiteljstva. Zagreb: Liber-Mladost, 1974.

Frimmová, Eva. "Der Humanismus in Pressburg am Ausgang des Mittelalters". U: Verdrängter Humanismus-Verzögerte Aufklärung, uredili Michael Benedikt, Reinhold Knoll i Josef Rupitz, 273-292. Klausen-Leopoldsdorf: Verlag LebenKunst-Wissenschaft, 1996.

Grendler, Paul F. The Universities of Italian Renaissance. Baltimore; London: The John Hopkins University Press, 2002.

Grmek, Dražen Mirko. "Verantius, Faustus". Dictionary of Scientific Biography, Vol. XIII, 613-614. New York: Scribner’s Sons, 1976.

Horvat, Vladimir. "Faust Vrančić i isusovci Alfonso Carrillio i Bartol Kašić". U: Zbornik o Faustu Vrančiću. Zbornik radova sa znanstvenog skupa "Obitelj Vrančić u hrvatskoj književnosti i znanosti", Šibenik 12.-14. rujna 1995, uredio Vilijam Lakić, 7-13. Šibenik: Gradska knjižnica "Juraj Šižgorić”, 2001.

Jurić, Šime. "Nepoznata izdanja 'Logike i etike’ Fausta Vrančića”. Prilozi za istraživanje hrvatske filozofske baštine 4/1-2 (7-8) (1978): 289-294.

Klaniczay, Tibor; Jankovics József, ur. Matthias Corvinus and Humanism in Central Europe. Budapest: Balassi Kiadó, 1994.

Klemm, Friedrich; Wissner, Adolf. Fausto Veranzio und seine "Machinae novae". München: Heinz Moos Verlag, 1965.

Kovač, Srećko. "Faust Vrančić i aristotelizam u logici". Prilozi za istraživanje hrvatske filozofske baštine 14/1-2 (27-28) (1988): 17-33. 
Kovač, Srećko. "Logika Fausta Vrančića". Prilozi za istraživanje hrvatske filozofske baštine 10/1-2 (19-20) (1984): 39-48.

Laird, Walter Roy; Roux, Sophie ur. Mechanics and Natural Philosophy before the Scientific Revolution. Berlin: Springer, 2008.

Lisac, Josip. "Hrvatski jezik i Faust Vrančić, s osobitim obzirom na Život nikoliko izabranih divic". U: Faust Vrančić, Život nikoliko izabranih divic, 145-147. Šibenik: Gradska knjižnica "Juraj Šižgorić”, 1995.

Lisac, Josip. "Hrvatski jezik Vrančićeva rječnika i njegove proze”. Filologija 59 (2013): 37-47.

Lisac, Josip. Faust Vrančić i drugi. Jezičnopovijesni ogledi. Šibenik: Gradska knjižnica "Juraj Šižgorić”, 2004.

Loderecker, Peter. Dictionarium septem diversarum linguarum, videlicet Latine, Italice, Dalmatice, Bohemice, Polonice, Germanice et Ungarice etc., Prag: 1605.

Mühleisen, Hans-Otto; Stammen, Theo, ur. Politische Tugendlehre und Regierungskunst. Tübingen: Niemeyer Verlag, 1990.

Muljević, Vladimir. "Hrvatski znanstvenici Antun i Faust Vrančić". Encyclopaedia moderna, 14/42 (1993), br. 2: 122-136.

Muljević, Vladimir. Faust Vrančić, prvi hrvatski izumitelj. Zagreb: Hrvatska zajednica tehničke kulture, 1998.

Plejić Poje, Lahorka. "Kako jedno zrcalo pričisto: Bartol Kašić i poslijetridentska prozna hagiografija”. U: Tridentska baština. Katolička obnova i konfesionalizacija u hrvatskim zemljama. Zbornik radova, uredile Zrinka Blažević i Lahorka Plejić Poje, 363-376. Zagreb: Matica hrvatska, 2016.

Rose, Paul Lawrence; Stillman, Drake. "The Pseudo-Aristotelian Questions of Mechanics in Renaissance Culture". Studies in the Renaissance 18 (1971): 65-104.

Roy Laird, Walter. “The Scope of Renaissance Mechanics". Osiris 2 (1986): 43-68.

Setton, Kenneth M. Venice, Austria and the Turks in the Seventeenth Century. Philadephia: The American Philosophical Society, 1991.

Tatarin, Milovan. Bludnica i svetica. Starohrvatska legenda o Mariji Egipćanki. Zagreb: Naklada Ljevak, 2003.

Vončina, Josip. "Vrančićev rječnik". Filologija 9 (1979): 7-36.

Vrančić, Faust. Xivvot nikoliko izabranih divvicz. Romae: apud Aloisium Zannettum, 1606.

Vulić, Sanja. “Još ponešto o Vrančićevim nazivima mjeseci u godini”. Čakavska rič XLIV (2016), br. 1-2: 131-139.

Vulić, Sanja. "Vrančićev leksik u kontekstu hrvatskoga leksika u prošlosti i sadašnjosti”. U: Faust Vrančić i njegovo doba. Zbornik radova s Međunarodnog 
znanstvenog skupa održanog u povodu 400. obljetnice objavljivanja Novih strojeva Fausta Vrančića, uredili Marijana Borić, Zrinka Blažević i Bojan Marotti, (u tisku). Zenić, Milivoj. U pohvalu od grada Šibenika: pisana riječ o najstarijih vremena do danas. Šibenik: Gradska knjižnica “Juraj Šižgorić”, 2002. 


\section{Faust Vrančić (1551 - 1617) and intellectual culture of his age}

Zrinka Blažević

Department of History

Faculty of Humanities and Social Sciences

University of Zagreb

Ivana Lučića 3

10000 Zagreb

Croatia

E-mail: zblazevi@ffzg.hr

\section{Summary}

Faust Vrančić (1551 - 1617) is one of the most versatile Croatian humanists and polymaths whose scientific, literary and political activities deeply marked both Croatian and European intellectual culture and at the turn of the $16^{\text {th }}$ century. In the manner typical for late humanist scholar, Vrančić assimilated, combined and creatively modified features of various intellectual traditions which fashioned the complex structure of the Renaissance episteme, from Aristotelism and Scholastics to Renaissance Humanism and Reformational Catholicism. By examining technical, linguistic, philosophical, hagiographical and historical works by Faust Vrančić, the complex configuration of late Humanist intellectual culture between Meditteranean and Central Europe has been highlighted. As a consequence, it can be stated that Vrančić was not only its highly competent participant but also one of its most creative and imaginative creators.

Keywords: Faust Vrančić, works, $16^{\text {th }}$ century intellectual culture, Renaissance episteme 